\title{
A Educação Física entre o projeto social da modernidade sólida e da modernidade líquida
}

Sidinei Pithan da Silva*

\section{Resumo}

O presente texto ${ }^{1}$ tematiza, a partir do pensamento de Bauman, a constituição da identidade e legitimidade social da educação física no contexto de transição da modernidade sólida para a modernidade líquida. Decorre deste pensamento a compreensão da natureza da crise que atravessa o discurso identitário da Educação Física. De outra forma, o texto sinaliza para os limites e possibilidades do discurso educacional moderno e pós-moderno. Nesse contexto, descreve um cenário moderno marcado por dois momentos distintos, o da modernidade em sua fase sólida e o da modernidade em sua fase líquida. O primeiro, da modernidade sólida, a condição social de vigilância, de racionalização, de controle, cumpre o papel funcional/adaptativo de colocar todos sob a mesma ordem rígida (sociedade administrada). O segundo, da modernidade líquida, a condição social de insignificância, de irracionalismo, cumpre o papel funcional de colocar e manter todos sob a mesma desordem flexível do mercado. Do enfoque cientificista e mecanicista do corpo e da Educação Física na modernidade sólida passamos ao enfoque relativista e esteticista do corpo e da Educação Física na modernidade líquida.

Palavras-chave: Educação Física; modernidade sólida; modernidade líquida.

\section{Physical Education between the social project of solid modernity and the of liquid modernity}

\section{Abstract}

Grounded on Bauman's thought, the present paper focuses on the constitution of social legitimacy and identity of Physical Education in the context of transition from solid to liquid modernity. This thought favors the understanding of the nature of the crisis that has crossed the identity discourse of Physical Education. The text signals the limits and possibilities of both the modern and the post-modern educational discourses. In this context, it describes a modern scenario that is marked by two distinct moments, the one of modernity at its solid stage, and that of modernity at its liquid stage. The first one, of solid modernity, social condition of surveillance, rationalization and control, performs the functional / adaptive role of putting everyone under the same rigid order (managed society). The second one, of liquid modernity, of the social condition of insignificance and irrationalism, plays the functional role of putting and keeping everyone under the

\footnotetext{
* Professor Doutor da Universidade Regional do Noroeste do Estado do Rio Grande do Sul (Unijuí) e coordenador do colegiado em Educação Física. ljuí, Rio Grande do Sul.
} 


\section{Sidinei Pithan da Silva}

same flexible Market disorder. From the scientific, mechanic focus of both the body and the physical education in solid modernity we have moved to the relativist and esthetic focus of body and physical education in liquid modernity.

Keywords: Physical Education; solid modernity; liquid modernity.

\section{Introdução}

Este texto pretende, a partir dos escritos de Zigmunt Bauman, contribuir no processo de explicitação e compreensão de algumas relações implicadas na produção do campo epistemológico, identitário e legitimatório em Educação Física num contexto de transição sócio-histórica da modernidade sólida para a modernidade líquida. A hipótese sustentada é a de que as novas teorizações acerca da identidade e da legitimidade da Educação Física (COLETIVO DE AUTORES, 1992; BRACHT, 1997, 1999, 2003, 2009; SANTIN, 1997; FENSTERSEIFER, 2001) expressam a crise paradigmática da modernidade (sólida). O novo contexto sócio-histórico, compreendido como um contexto de transição entre a modernidade sólida e a modernidade líquida, ajuda a definir e compreender a complexidade dos fatores implicados nas transformações da Educação Física. Explicitar alguns significados dos termos modernidade sólida e modernidade líquida consiste no desafio fundamental deste texto e sua contribuição para pensar a Educação Física.

A explicitação de alguns elementos constitutivos do projeto social da modernidade e da pós-modernidade e a contextualização do pensamento de Bauman em relação a estas constitui uma primeira parte do texto. A segunda parte tenta caracterizar os dois momentos da modernidade, um primeiro que se configuraria como compreendendo a modernidade em sua fase sólida e um segundo compreendendo-a em sua fase líquida. Depreende-se desse movimento certa compreensão desenhada para configurar a identidade, a legitimidade e 0 papel social da Educação Física ao longo da modernidade (BRACHT, 1999; 2003; 2009; OLIVEIRA, 2004). Outrossim, evidenciam-se as dificuldades de pensar, no contexto de crise da modernidade sólida, e emergência da modernidade líquida, os papéis sociais desejáveis para a Educação Física (DEVÍs; ALVENTOSA, 2004).

Os referenciais modernos ofereciam a segurança (os fundamentos universais) de uma relação "epistêmica" amparada na "razão subjetiva" (Kant) para pensar nestas finalidades sociais. Os referenciais pós-modernos (Lyotard e Derrida), característicos da fase líquida da modernidade, parecem desacreditar em qualquer forma de "razão" que se queira emancipatória, seja ela a razão histórica (Hegel), a razão crítica (Marx, Adorno e Horkheimer) ou mesmo a razão comunicativa (Habermas) e, portanto, parecem abandonar por completo o amparo numa forma de racionalidade (universal). Esses referenciais apontam 
para uma relação contingente, relativa, múltipla e particular. Nestas, predominam a força do múltiplo ao invés do uno, da diferença ao invés da dialética, do local, ao invés do universal. Bauman parece transitar com certa facilidade em torno dos dois projetos filosóficos e sociais mostrando as dificuldades e as potencialidades em ambos. Bauman denuncia nos modernos a ilusão da "certeza utópica", da confiança cega na ciência, na razão, na ordem, mostrando como ela nos conduziu ao caos no século XX e, nesse ponto, se aproxima do pensamento pós-moderno heideggeriano (constitutivo do pensamento de Foucault, Derrida e Rorty). De outra forma, Bauman (2001) denuncia o excesso de "incerteza utópica" presente nos teóricos pós- modernos, que desconfiam e abandonam qualquer projeto social de mudança futura, evidenciando a desordem, a fragmentação e o individualismo como marcas dos novos elementos de dominação constitutivos do mundo globalizado.

Bauman, de forma semelhante à Morin, que tematiza a emergência da complexidade do real, aponta a ambivalência constitutiva da linguagem e do real, o qual não se deixa capturar ou possui uma unilateralidade. Isso significa que Bauman, ao assumir esta perspectiva, consegue dialogar com autores de ambas as tradições modernas e pós-modernas, sem render-se a nenhuma delas. Isso significa, ainda que Bauman, em certo momento incorpora a perspectiva de Foucault, Derrida e Rorty, em sua crítica à razão moderna e, em certo momento, em sua fase tardia, os considera também prisioneiros de nosso tempo. Bauman está interessado, sobretudo, em analisar os discursos modernos e pós-modernos a fim de pensar e compreender a sociedade em que vivemos. Disso desdobram-se possibilidades para pensar a teoria social crítica, a teoria educacional crítica e consequentemente a própria teorização e intervenção em Educação Física.

\section{Modernidade, pós-modernidade e educação: um percurso em Zigmunt} Bauman

A emergência da modernidade constitui em si uma forma específica e única que se apresenta no Ocidente. Para Castoriadis (1992), ela comporta, em última instância, uma ambivalência. Ao mesmo tempo em que significa a luta pela autonomia e pela liberdade humana, ela representa uma nova forma de heteronomia e de dominação. Em Castoriadis, a ideia de modernidade comporta, portanto, dois significados histórico-sociais, que embora ambivalentes, a constituem: o da retomada do projeto da autonomia política e humana iniciado na Grécia clássica, sob a forma de uma razão crítica, e o da heteronomia deste projeto enquanto conversão deste em uma razão produtiva.

Bauman, num esforço de compreensão da modernidade, tematiza um de seus principais elementos, qual seja: a busca de estabelecimento, pela via do intelecto, da razão e da linguagem, de uma ordem que suprime a ambivalência do real. A modernidade começa, por assim dizer, enquanto ruptura de uma forma de compreender o real e o início de outra. A luta pela autonomia, pressupos- 


\section{Sidinei Pithan da Silva}

to da modernidade, assinalado por Castoriadis, converte-se, na interpretação de Bauman, numa luta pela tentativa de controlar o fluxo desordenado do real. Bauman entende que a questão da ordem é tratada diferentemente pelos modernos. Estes perseguem obsessivamente a "determinação contra a ambiguidade, da precisão semântica contra a ambivalência, da transparência contra a obscuridade, da clareza contra a confusão" (BAUMAN, 1999, p.14).

Se o projeto da modernidade comporta a ideia de um projeto social e histórico vinculado à autonomia e à democracia, cumpre compreender porque ele se converte num projeto de heteronomia e de dominação. Castoriadis e Bauman possuem uma interpretação muito próxima a de Freud quanto a este problema. A modernidade significa em Freud (1978a; 1978b) um projeto humano de realizar o irrealizável, de controlar o incontrolável, de dominar o incapaz de ser dominado. A modernidade constitui um impulso, uma crença desmesurada nas forças da razão, imaginando nestas a saída salvacionista para o mundo humano. Adorno (2003) e Horkheimer (1985), em interpretação semelhante, mostram que o grande drama da modernidade, da crise da razão moderna, constituiu-se na constituição de uma sociedade administrada, vinculada a uma lógica identitária.

O problema da modernidade, de sua contradição, de sua ambivalência, surge nesta passagem de Bauman, numa forma muito próxima ao diagnóstico feito por Weber (1980) sobre a modernidade, no sentido que compreende que a instância da "racionalização" tornara-se a instância predominante na lógica da vida social moderna. A vida social moderna, sob esta interpretação, é uma vida social construída, planejada e administrada por especialistas. As forças da razão encontram-se agora sustentadas em uma nova forma de intelecto. Este destitui as formas tradicionais de autoridade e de poder que fundamentavam e normatizavam a vida social na medievalidade. A racionalidade científica, enquanto esforço da razão, para autojustificar-se e substituir a racionalidade teológica, comporta a ideia de uma determinação e de estabelecimento de uma ordem definitiva ao caos. "De fato, pode-se definir a modernidade como a época, ou o estilo de vida, em que a colocação em ordem depende do desmantelamento da ordem tradicional, herdada e recebida; em que ser significa um novo começo permanente" (BAUMAN, 1998, p. 20).

Adorno e Horkheimer (1985) interpretaram que este impulso e movimento autoes-clarecedor da modernidade converteu-se no seu oposto, uma vez que se ancorou numa razão formal, que se sobrepõe à contingência. $O$ formalismo lógico e matemático, do lado da ciência positivista, corresponde aos interesses imediatos do mundo burguês, qual seja: declarar-se neutro e independente do mundo social e histórico do qual faz parte e o constitui. Com isso, o ideal emancipatório, pressuposto declarado e assumido pelo racionalismo subjetivista, enquanto máxima da modernidade, torna-se prisioneiro deste formalismo característico do positivismo mecanicista que, ao não tematizar a complexidade do mundo social e histórico nascente, tampouco as contradições que engendra, 
mistifica as possibilidades reais para engendrar a liberdade e a emancipação. Assim, em última instância, os pressupostos da política, da ética e da educação, na modernidade, pelo viés do racionalismo subjetivista e metafísico, vincular-se-ão ao mundo produtivo e social nascente, sendo "tecnicizados". "No seu decidido impulso para uma eficiência técnica maior, a competência especializada deve dissolver todas as 'totalidades' - pois se concentra, ao contrário, nos seus segmentos acessíveis e controláveis" (BAUMAN, 1999, p. 241).

Nesse sentido, a modernidade é marcada por uma racionalização crescente de todas as esferas da vida social, como bem apontou Weber, Adorno, Horkheimer, Habermas e Castoriadis, na esteira de Marx, que passam a ser tuteladas pelos interesses do mundo produtivo. Bauman, neste rastro deixado pela interpretação da tradição crítica, e muito influenciado por Derrida, Rorty, Lyotard, Heller e Foucault, tematiza a ânsia da modernidade por livrar-se do entulho, do caos e por uma ordem definitiva no real. A modernidade é interpretada por Bauman como o movimento que pretende livrar-se do diferente, do anormal, do incomensurável, da ambivalência. Esta ânsia encontra-se implícita na própria forma de compreensão da razão. A tentativa da pureza, da ordem, do planejamento e controle de todas as variáveis encontra-se implícito na noção de razão produzida pelos modernos. Colocar uma ordem no caos torna-se uma forma encontrada pelos modernos para a conquista da segurança. A ciência moderna nasce "da esmagadora ambição de conquistar a Natureza e subordinálas às necessidades humanas” (BAUMAN, 1999, p. 48).

O termo pós-moderno, para Bauman, enquanto definidor de nossa época histórica, parece impróprio, porque parece assinalar a morte de algo que ainda continua em atividade. No entanto, a atual crise da educação apresenta algumas diferenças radicais das crises que atingiram a "fase sólida da modernidade". Estas questões referem-se ao próprio sentido da educação. Não se tratam de reformas simples, nas margens da educação, mas do questionamento radical dos paradigmas que animaram a educação moderna. Na interpretação de Bauman (2002), o caráter móvel e fluido da atual etapa do capitalismo é decorrente das novas políticas econômicas. "Em nosso mundo volátil de mudanças instantâneas e erráticas, os hábitos arraigados, as estruturas cognitivas sólidas e a preferência por valores estáveis, objetivos últimos da educação ortodoxa, transformaram-se em desvantagens" (BAUMAN, 2002, p. 51). Pelo menos foram assim rejeitados pelo mercado do conhecimento, para o qual (da mesma forma que para qualquer outro mercado) toda lealdade, vínculos irrompíveis e compromissos de longo prazo são anátema - obstáculos a serem eliminados do caminho.

\section{Modernidade sólida, modernidade líquida e Educação Física}

Poderíamos entender a lógica constitutiva da modernidade - em sua fase sólida -, associada inicialmente com as categorias do pensamento (filosófico) moderno (Descartes, Kant e Hegel) em sua busca "construcionista" e "sis- 


\section{Sidinei Pithan da Silva}

temática" pela fundamentação da razão (ciência) a partir dos pressupostos da ordem, da certeza e do progresso. E poderíamos entender a modernidade em sua fase líquida associada com a crise do pensamento moderno e a ascensão do pensamento pós-moderno (Vattimo, Lyotard, Deleuze, Foucault e Derrida), com sua ênfase na "desconstrução" dos fundamentos da (razão) ciência, afirmando novos pressupostos para o real - desordem, incerteza e diferença. $O$ pensamento pós-moderno anuncia o reino do fragmento, contra a totalização, do descontínuo e do múltiplo, contra a teleologia das grandes narrativas, do particular contra o geral, do corpo contra a razão (ROUANET, 2004). Sobre este pressuposto, a interpretação do pensamento pós-moderno (em comparação com o pensamento moderno) nos permite entender as novas formas de legitimação do real que ocorrem na fase de acumulação flexível do capitalismo - modernidade líquida (flexível) - e que acabam por influenciar o pensamento educacional e a constituição dos parâmetros para pensar a Educação Física.

O projeto da razão prática, intuito da filosofia racionalista moderna, de Descartes até Kant e Hegel, significava uma tentativa de não produzir um conhecimento puramente especulativo e vazio sobre o homem. Mas, pelo contrário, de produzir um conhecimento que pudesse orientar o homem em relação ao seu destino histórico e social. A possibilidade de criar e produzir novos "universais" que pudessem conduzir (educar) a humanidade rumo a um destino melhor da espécie humana tornava o projeto filosófico moderno ligado ao destino histórico da humanidade (MARCUSE, 2004). "A imaginação dos racionalizadores é tentada pela perspectiva de um estado de perfeição última e estável, um Estado do qual terá sido eliminada a própria possibilidade de desafio à ordem estabelecida" (BAUMAN, 1999, p. 47).

Enquanto a modernidade parece ter privilegiado o culto "à razão, ao positivismo, ao tecnocentrismo", aos paradigmas monológicos e às visões universalizantes do mundo e da cultura, a pós-modernidade, pelo contrário, parece ter optado pelo "culto da diferença, da heterogeneidade, da indeterminação e da fragmentação" (HARVEY, 2000, p. 20). Essas formas parecem ser as formas de liberar o discurso cultural da camisa de força, ou da "janela de ferro" da racionalidade moderna. A preferência pelo estudo do caráter micro ao invés do macro, da superfície ao invés da profundidade, do particular ao invés do universal, da descontinuidade ao invés da continuidade assinala condições emergentes na teorização pós-moderna. Se a episteme moderna lutou contra os mitos da metafísica medieval, a episteme pós-moderna luta com todas as forças contra os mitos da ciência. Desmistificar e colocar em questão as categorias mais fortes da modernidade constitui a empreitada que vários pensadores contemporâneos se encarregaram de fazer para poder irromper uma nova concepção do mundo em que vivemos. Dentre eles destacam-se, apesar das diferenças, Lyotard, Vattimo, Kuhn, Feyerabend, Foucault, Deleuze e Derrida, Baudrillard e Rorty. Estas muitas críticas à modernidade advêm, em grande parte, das considerações realizadas por Nietzsche e Heidegger em relação à metafísica moderna. 
A teoria social e educacional, no projeto social da modernidade sólida, são marcadas, fundamentalmente, pelos elementos constitutivos do "cientificismo" e do "racionalismo" da filosofia do sujeito, os quais ajudam a legitimar e, se "legitimam", no contexto do liberalismo e do capitalismo em sua fase industrial - sólida. Seus fundamentos estão vinculados ao projeto do lluminismo, portanto à filosofia das luzes. Os sentidos e as finalidades da educação (física) nesta etapa do capitalismo seguem modelos mais duráveis, sólidos, estáveis, uma vez que, embora haja uma transformação ininterrupta dos modos de produção e das relações sociais e culturais - como marca central da modernidade -, ela é ainda determinada, nesta fase, por um modelo de acumulação rígido, mecânico e lento, o que implica uma maior "durabilidade" do projeto educacional. Os conhecimentos técnico-científicos ajudam a "alimentar" e "expandir" a lógica da sociedade produtora de mercadorias, contribuindo não apenas para a melhoria "moral" do homem (busca da perfeição disciplinar), como também para aumentar as forças propulsoras da economia. As forças da razão encontram-se aplicadas, neste projeto, em termos educacionais, na edificação das subjetividades necessárias ao "progresso" econômico e à moderna "democracia" representativa - constituição do Estado Nacional. Os interesses da Educação Física, bem como sua justificação social, se referem, nesse momento, à dimensão física e corporal das pessoas, sem se referir à "dimensão intelectual ou afetiva" (DEVİS; ALVENTOSA, 2004).

A crise deste modelo de racionalidade - o seu possível fim e esgotamento - como fora afirmado pela pós-modernidade - ao longo do século XX encontra-se vinculada não apenas a uma transformação nas esferas filosóficas, políticas, culturais e técnico-científicas (o que é totalmente plausível, visível e constatável) como também a um novo contexto de reprodução sociometabólica do capitalismo, em que predomina um modelo econômico de acumulação mais flexível. O capital se reproduz sob uma base mais móvel e flexível, em que a durabilidade e a certeza, marcas da fase industrial e sólida do capitalismo, são substituídas pela pouca durabilidade e a incerteza. O Estado Nacional (liberal) recua, privatizando e responsabilizando os próprios sujeitos (trabalhadores) por suas vidas, deixando-os governados pelas forças do mercado transnacional. $O$ princípio apontado por Marx, "tudo que é sólido desmancha no ar", torna-se, mais do que nunca, materializado e manifesto na lógica do capitalismo tardio modernidade líquida (condição pós-moderna - Harvey - modernidade reflexiva Beck e Giddens - modernidade líquida - Bauman, modernidade singular/tardia - Jameson (2005).

A produção e o consumo, na modernidade líquida, dão-se agora numa nova plataforma - global - transnacional - em que o capital mundializado reproduz-se e flui numa velocidade nunca vista. O capital, sob forma de mercado globalizado, desregulamentado, assume, agora de forma transparente, o lugar do Estado - controlando e determinando o ritmo da vida social e cultural. A ideia de busca de "fundamentos" duradouros, universais, estáveis, que se tornara o solo comum da educação moderna (através do racionalismo e do mecanicismo), 


\section{Sidinei Pithan da Silva}

(e da filosofia da história de Kant e Hegel) na construção do moderno trabalhador e cidadão, tornou-se agora "obstáculo" à realização do reino da mercadoria. A efemeridade, a superficialidade e a flexibilidade devem ser os pressupostos epistêmicos que orientam a educação e a formação do trabalhador e consumidor deste <mercado globalizado>. "A 'desregulamentação' torna-se a palavra da hora e o princípio estratégico louvado e praticamente exibido pelos detentores do poder" (BAUMAN, 2003, p. 42).

O projeto social da modernidade sólida parecia corresponder a certa fase do capitalismo industrial nascente, em que se estruturavam as economias nascentes a partir de uma realidade de expansão do conhecimento sob forma de produção de artefatos tecnológicos mais duráveis. A divisão do trabalho e da organização produtiva procura orientar-se, nessa fase, pelos pressupostos do planejamento racional, implicando mais ritmo à produtividade. O planejamento segue modelos mais duráveis e rígidos, na tentativa de assegurar o controle pleno das situações e adversidades. "Sob diversos relatos e assinaturas de renome, a modernidade conjugou a avidez de divisão e de classificação do real com a vontade de sistematizar tudo de baixo de somente uma conta (ratio), assim como a luz do sol ilumina os objetos a partir de uma mesma claridade" (THAYER, 2002, p. 26).

Bracht (2009) pontua, nesse contexto que, em relação à Educação Física, há um deslocamento na concepção de corpo. A incorporação de novos referenciais permite romper com o positivismo imperante na área. O corpo é compreendido como uma construção simbólica. Há uma quebra da hegemonia do discurso médico-biologicista e uma abertura para uma pluralidade de sentidos. Não há apenas uma perspectiva científica correta, ou tampouco um único referencial teórico capaz de guiar e orientar a educação corporal. Bracht assinala este novo lugar e status do corpo na modernidade líquida para pensar a construção das subjetividades e identidades. Segundo ele:

Se na Educação Física sólida o corpo como natureza tem seu sentido marcado pelas leis da natureza (aspecto que possui forte poder normativo - imperativo da natureza!), na modernidade líquida o corpo é entendido como construção simbólica, portanto aberto à história; temos então uma proliferação e diversificação de sentidos e práticas corporais (fortemente orientadas no mercado como vou argumentar à frente). [...] Em relação ao corpo podemos perceber deslocamentos como: do ascetismo para o hedonismo (ou uma melhor convivência entre os dois); do corpo produtivo para o corpo consumidor; do corpo dócil para o corpo flexível (Veiga Neto, 2008). (Pensemos também, nas práticas corporais ligadas ao turismo, aos SPAS, à estetização tanto no sentido morfológico como no das experiências/sensações estéticas. Sensações que nunca podem ser plenamen- 
A Educação Física entre o projeto social da modernidade sólida e da modernidade líquida

te satisfeitas, que levam a uma busca incessante e infindável por sempre novas sensações (cultura do efêmero). O corpo deixa de ser visto apenas como alvo do controle ascético, pra ser fonte de prazer e não mais apenas meio para alcançar outros fins mais nobres, passando as sensações corporais para o status de finalidade e sentido do viver. (BRACHT, 2009, p. 9)

Há, durante a modernidade sólida, na leitura de Bauman (2002), uma busca pela solidez, pela durabilidade dos produtos, pela certeza e harmonia. Em seu estágio sólido, hoje passado, destaca Bauman (2002, p. 46), a modernidade - em si mesma uma reação à fragilidade do ancien regime prémoderno que rapidamente perdeu seu poder de controle - era obcecada pela durabilidade. A forma emergente de vida social, na segunda metade do século $\mathrm{XX}$, assegura Bauman, não corresponde à entrada na pós-modernidade, mas sim no "estágio líquido da modernidade". Nesse estágio, temos não somente a perda da noção de conhecimento e de educação como algo duradouro, para toda a vida, mas como algo efêmero e circunstancial. Essa realidade, característica da sociedade de consumo atual, explicita a emergência da incerteza, da superficialidade, da velocidade e da estetização do cotidiano (BERMAN, 2006).

A Educação Física, em sua tentativa de autoafirmação no interior da escola e da sociedade, buscou referenciar-se pelo modelo de cientificidade da modernidade sólida. Mais do que isso, buscou cumprir as finalidades sociais projetadas na educação dos corpos para a construção dos ideais modernos (SOARES, 2004). A noção de leis da natureza, de um conhecimento seguro e confiável que pudesse educar os corpos para que pudesse controlar os corpos rumo à perfectibilidade serviu como forma de padronizar e tornar a prática pedagógica mais confiável e segura. "Um elemento importante deste universo era a ciência de caráter mecanicista, que fornecia coerência, que legitimava a visão mecânica de corpo" (BRACHT, 2003, p.16). Esta compreensão correspondia a um ideal educativo funcional e adaptativo, em que não se vislumbrava como a Educação Física poderia contribuir para pensar uma perspectiva emancipatória. O caldo cultural da modernidade sólida reservou somente funções funcionais/ adaptativas aos profissionais da Educação Física. O corpo da Educação Física era somente o corpo físico (dócil), necessário ao trabalho e à moral disciplinar. O caráter emancipatório e crítico da Educação Física, ou seja, sua própria autocompreensão política, só se dá num contexto de crise dos ideais modernos e dos fundamentos da racionalidade moderna.

A partir desse pressuposto, compreende-se que a forma identitária assumida pelos profissionais de Educação Física se amparasse no modelo de racionalidade (cientificidade) projetada pela modernidade sólida (racionalista), na qual o corpo ocupava um lugar secundário. O lugar secundário da Educação Física, no interior da escola e da sociedade, se deve, em grande medida, ao lugar secundário do corpo no interior do imaginário acerca do que é considerado 
um conhecimento válido (na cultura racionalista moderna). Uma nova forma de tematização do corpo, produzida contemporaneamente, tem permitido extrapolar a noção de conhecimento em Educação Física. Destaca-se a afirmação de Bracht quando pontua que "o corpo, que sempre foi hierarquicamente secundarizado diante da razão, parece começar a recuperar uma certa dignidade ontológica" (BRACHT, 2001, p. 74). Isso significa uma nova forma de pensar a identidade e a função social da área, mas também significa a possibilidade de pensar nas implicações que a negação do racionalismo moderno tem para a Educação Física. A condição parece ser evitar o dualismo moderno entre pensamento (razão) e movimento (experiência), para incorporar o movimento/pensamento e o pensamento/movimento, conforme apontou Bracht em outro momento (1999). Em suma, na modernidade líquida, se trata da ideia de que os alunos precisam se converter em praticantes inteligentes e não apenas "imitadores ou repetidores mecânicos de atividades físicas" (DEVİS; ALVENTOSA, 2004, p. 45).

\section{Considerações finais}

Neste contexto, compreender as relações entre o processo de transição da modernidade sólida para a modernidade líquida / flexível na produção dos discursos e referenciais que pensam a identidade, a legitimidade e a justificação da Educação Física no contexto social, constitui uma tarefa presente e inadiável. Na modernidade (líquida) os referenciais em Educação Física incorporam contribuições de perspectivas teóricas muito distintas, enfatizando, basicamente, guinadas epistemológicas radicais. O corpo assume um lugar de destaque nas tematizações acerca da saúde, do lazer, do conhecimento, da sociedade, da educação física. A linguagem deixa de ser compreendida como dimensão instrumental do humano, enquanto faculdade, para ser assumida como perspectiva constitutiva de nossa relação com o mundo; o que significa um reconhecimento do caráter interpretativo do conhecimento e mesmo de valorização da hermenêutica. De outra forma, a noção de linguagem também significa e expressa a dimensão conflituosa em que se estabelece a luta pelo signo e pelo significado das coisas e do mundo. A noção de cultura articulada à noção de linguagem e à noção de sociedade cumpre um papel predominante neste cenário. Não se chega a uma sem passar pela outra. O corpo manifesta-se como entrecruzamento das questões sócio-culturais e políticas, sendo não apenas instrumento/apêndice da vida social/existencial, mas dimensão constitutiva da mesma. Esta forma de compreensão emerge marcada num contexto de crise dos referenciais típicos da modernidade sólida.

Na Educação Física (escolar), a categoria cultura corporal (de movimento) passa a ser incorporada como instância importante para pensar o trabaIho pedagógico. A ação docente que era vinculada ao corpo físico (orgânico), ou à prática esportiva e competitiva durante a modernidade sólida, passa a ser vinculada aos elementos da cultura corporal de movimento na modernidade líquida. Isso significa pensar o trabalho do professor enquanto um sujeito político- 
cultural imbricado na trama das relações linguísticas, culturais, sociais e históricas. O trabalho do professor, no interior da escola, deixa de ser meramente a produção do mesmo, do padrão exigido socialmente e ele passa a ser alguém que problematiza as esferas que estão no entorno da produção do corpo. Com isso, a dimensão pedagógica da profissão aparece vinculada à dimensão política e sócio-histórica. Um compromisso com a dimensão cultural, social e políti$\mathrm{ca}$, que permeia a prática pedagógica passa a ser a tônica do discurso. A reflexividade assume um lugar de destaque, uma vez que não se trata de produzir um tipo único de corpo, marcado por um ideal metafísico, mas trata-se de problematizar todos os tipos corporais estabelecidos historicamente.

O fato é que o lugar do corpo na sociedade contemporânea tem sido incorporado na cultura da sociedade líquido-moderna de forma esteticista, relativista e mercadológica. Passamos do corpo (biológico) vigiado, reprimido, controlado e explorado socialmente, na modernidade sólida, ao corpo insignificante, estetizado e erotizado (da cultura) na modernidade líquida. Passamos de uma etapa do capitalismo nacional, em que a política ainda conseguia fazer frente, impor limites ao capital (regulamentação) a uma etapa em que o capital transnacional consegue se reproduzir sem os limites da política (desregulamentação). A crise identitária sentida pelos profissionais de Educação Física se deve em grande medida a este deslocamento em relação às funções sociais da Educação Física em relação à educação corporal e às transformações na esfera da política econômica. $\mathrm{Na}$ modernidade sólida, as funções sociais estavam claramente definidas, a partir do recorte biológico, privilegiando a adaptação/educação através da disciplina, do controle e da vigilância (higienismo, militarismo, esportivismo). Na modernidade líquida, a partir do recorte cultural, abre-se um imenso leque para compreender a modernidade do corpo, mas ao mesmo tempo as formas e forças de dominação social (globalizadas, extraterritoriais) sobre ele não se dão mais de forma clara e administrada como fora na modernidade sólida, mas sim de forma caótica, desordenada e instável. Os compromissos assumidos e claramente delineados na constituição da sociedade moderna entram em crise na sociedade líquidomoderna e, com ele, entram em crise os ideários educacionais que sustentavam e orientavam o trabalho dos educadores. Bauman parece ser um autor importante neste cenário, principalmente porque sem se entregar ao formalismo moderno, e tampouco ao relativismo pós-moderno, nos mostra caminhos para pensar nos desafios educacionais, políticos e epistêmicos que temos na modernidade líquida.

\section{Referências}

ADORNO, T. W. Educação e emancipação. Rio de Janeiro: Paz e Terra, 2003.

ADORNO, T.N.; HORKHEIMER, M. Dialética do esclarecimento: fragmentos filosóficos. Rio de Janeiro: Jorge Zahar, 1985.

BRACHT, V. Educação Física e aprendizagem social. 2. ed. Porto Alegre: Magister, 1997. 
Sidinei Pithan da Silva

BRACHT, V. Educação Física \& Ciência: cenas de um casamento infeliz. ljuí: Ed. Unijui, 1999.

Saber e Fazer Pedagógico: acerca da legitimidade da Educação Física como componente curricular. In: CAPARRÓZ, F. E. (Org.). Educação Física Escolar: política, investigação e intervenção. vol. 1. Vitória: PROTEORIA, 2001.

. \& CRISORIO, R. (Orgs.). A Educação Física no Brasil e na Argentina: identidade, desafios e perspectivas. Campinas: Autores Associados; Rio de Janeiro, PROSUL, 2003.

. Formação profissional, currículo e prática pedagógica. In: Palestra no XVI Conbrace E III Conice-2009 (mimeo).

BAUMAN, Z. O mal-estar da pós-modernidade. Rio de Janeiro: Jorge Zahar, 1998. 1999.

Globalização: as conseqüências humanas. Rio de Janeiro: Jorge Zahar,

Em busca da política. Rio de Janeiro: Jorge Zahar, 2000.

Modernidade líquida. Rio de Janeiro: Jorge Zahar, 2001.

Desafios educacionais da modernidade líquida. Revista Tempo Brasileiro. Rio de Janeiro, jan./mar. n. 148, 2002.

Comunidade: a busca por segurança no mundo atual. Rio de Janeiro: Jorge Zahar, 2003.

Medo líquido. Rio de Janeiro: Jorge Zahar, 2008.

BERMAN, M. Tudo que é sólido se desmancha no ar: a aventura da modernidade. 2. ed. São Paulo: Companhia das Letras, 2006.

CASTORIADIS, C. As encruzilhadas do labirinto III: o mundo fragmentado. São Paulo: Editora Paz e Terra, 1992.

COLETIVO DE AUTORES. Metodologia do ensino de Educação Física. São Paulo: Cortez Editora, 1992.

DARIDO, S. C.; RANGEL, I. C. A. Educação Física na escola: implicações para a prática pedagógica. Rio de Janeiro: Guanabara koogan, 2005, p. 40.

DEVÌS, J. D.; ALVENTOSA, J, P. M. Las Funciones de La educación física escolar: de la modernidad a la postmodernidad. In: CAPARRÓZ, F. E.; ANDRADE FILHO, N. F. (Orgs.). Educação Física Escolar: política, investigação e intervenção. Vol. 2. Vitória: UFES, LESEF: Uberlândia: UFU, NEPECC, 2004.

FENSTERSEIFER, P. E. A Educação Física na crise da modernidade. ljuí: Ed. UNIJUÍ, 2001.

FREUD, S. O futuro de uma ilusão. São Paulo: Abril Cultural, 1978a. 
FREUD, S. O mal-estar na civilização. São Paulo: Abril Cultural, 1978b.

HARVEY, D. Condição Pós-Moderna. 15. ed. São Paulo: Loyola, 2006.

HELLER, A.; FEHÉR, F. A condição política pós-moderna. Rio de Janeiro: Civilização Brasileira, 2002.

JAMESON, F. Modernidade singular: ensaio sobre a ontologia do presente. Rio de Janeiro: Civilização Brasileira, 2005.

LYOTARD, J. F. Reescrever a Modernidade. In: 0 inumano: considerações sobre o tempo. Lisboa: Estampa, 1990, p. 33-43.

A condição pós-moderna. 7. ed. Rio de Janeiro: José Olympio, 2002.

MARCUSE, H. Razão e revolução: Hegel e o advento da teoria social. 5. ed. São Paulo: Paz e Terra, 2004.

OLIVEIRA, V. M. O que é Educação Física. 11. ed. São Paulo: Brasiliense, 2004.

ROUANET, S. P. As razões do iluminismo. Companhia das Letras, 2004.

SANTIN, S. Educação Física: uma abordagem filosófica da corporeidade. ljuí: UNIJUI, 1987.

SOARES, C. Educação Física: raízes européias e Brasil. 3. ed. Campinas: Autores Associados, 2004.

THAYER, W. A crise não moderna da universidade moderna. Belo Horizonte: Editora UFMG, 2002.

WEBER, M. A ética protestante e o espírito do capitalismo. In: Max Weber. Coleção os pensadores: Abril Cultural, 1980.

Nota

1 Este estudo foi apresentado parcialmente no XVII Congresso Brasileiro de Ciências do Esporte (Conbrace) e no IV Congresso Internacional de Ciências do Esporte (Conice) - 2011 em Porto Alegre-RS.

\section{Correspondência}

Sidinei Pithan da Silva - Universidade Regional do Noroeste do Estado do Rio Grande do Sul, Departamento de Pedagogia. Rua do Comércio, 1364. São Geraldo, CEP: $98700-000$ - ljuí, RS.

E-mail: sidinei.pithan@unijui.edu.br 